\title{
DON'T SMOKE, DON'T DRINK, DON'T FUCK: TOWARDS A THEORY OF STRAIGHT-EDGE CULTURE
}

Erin Foster

(I) Don't smoke

Don't drink

Don't fuck

At least I can fucking think

I can't keep up

Can't keep up

Can't keep up

Out of step with the world.

(Minor Threat, “Out of Step”)

Drugs, alcohol, and sex - the forbidden fruits of youth - signify for many adolescents a momentous step towards adulthood. Simultaneously prohibited and fetishized by popular culture, these elements of enigmatic temptation have provided endless clichéd fodder for decades of countless rock and roll songs, coming-of-age teenpics, and "Just Say No" campaigns. Likewise, most youth subcultures are primarily defined by which vices certain groups prefer most. What would a mod be without her pills? The greaser without his cigarettes? The punk without his beer? The hippie without her free love and LSD?

As Christine Griffin points out, youth and moral panic have been virtually synonymous since adolescence was “discovered” by G. Stanley Hall in 1904 (12). Ever since, the moral panic angle has remained a principal driving force in the field of youth culture research. A few scholars, such as Angela McRobbie and Sarah Thornton, have criticized the limitations of this type of research, attempting in their own work to open up discourse rather than confine subcultures to a static explanation. ${ }^{1}$ It is to this relatively new tradition of subcultural theory that I wish to contribute my own work.

This paper will be an examination of "straight-edge" youth culture, perhaps the only non-religion based subculture in which its members actively 
refrain from drug and alcohol use and casual sex as a form of societal rebellion. ${ }^{2}$ Straight-edge youth view these substances and activities as crutches that obstruct positive living and critical thinking and wreak chaos and injustice on society. Some straight-edgers have expanded the initial "no drugs, no alcohol, no sex" philosophy to include no caffeine, no prescription drugs, no meat or fish, and/or no dairy products. While straight-edge is not inherently political, a large number of members have interpreted politics as a logical extension of their "sXe" lifestyle:

Once you have regained control over your life, the desire to help others and to make a positive contribution to your culture, society, and community by addressing issues of social justice is a very natural thing to do. ${ }^{3}$

All quotes in this paper were gathered either through personal email correspondence with self-proclaimed straight-edgers or from the message boards of http://www.straightedge.com, considered by many participants to be the most active and reliable center of discourse for the online straight-edge community. An additional source I found invaluable was the alt.punk.straight-edge FAQ (frequently asked questions). The FAQ, which originated in 1997, is the most comprehensive description of the straight-edge subculture that I could find. The document is an amalgam of many sources and opinions continually updated by its maintainer, Lars Norved. Anyone who considers himself or herself straight-edge can contribute information to it via email. Due to this collective authorship, the information within the FAQ reflects the mutable and often contradictory nature of the straight-edge culture.

In this paper, I will focus on how the online straight-edge community continually and dynamically redefines and adapts itself as a group, defying static constructions so often found in subcultural theory. This analysis should not be considered a representation of the entire subculture; rather, my scope is limited to the virtual straight-edge community as it exists historically in 2000. Because this is the first academic examination of straight-edge of which I'm aware, I cannot deal with every aspect of the culture as completely as the material deserves. It is my hope that this work will prompt further studies of this complex and fascinating youth culture.

\section{Why all the rules?}

Straight-edge isn't about rules. It's a philosophy about being in control of your own actions and making decisions for yourself. As a result, you'll choose not to smoke, drink, sleep around, or eat meat; but these choices may be different to different people.

$$
\left(\text { Lantrel, age 24) }{ }^{4}\right.
$$

When I hear the word rules, I think of something I want to do but can't. I see straight-edge as a commitment that I proudly live by.

$$
\text { (Kaitlin, age 19) }{ }^{5}
$$


Subcultural theorists have employed the term homology to refer to the symbolic fit between the values and lifestyle choices of particular youth groups and the stylistic elements used to reinforce these concerns. Straight-edge homology is particularly important to examine because its members consider the lifestyle choice a lifetime commitment; there is no such thing as a weekend straight-edger. Though the majority of straight-edgers (especially those online) are middle- to upper class, the subculture as a whole rejects class distinctions among members. According to general consensus, females make up a significant portion of the community both virtually and in person. And although I didn't speak directly to any homosexual straight-edgers, almost everyone I spoke to considered the subculture relatively gay-friendly. Much more research remains to be done on how straight-edge varies within demographics of gender, race, class, and sexuality.

There is an ongoing and heated debate within straight-edge whether or not the lifestyle should be considered a subculture or a movement, or if it is strictly a personal choice. Those who view straight-edge as a subculture typically have a large amount of friends in their local area who share their views, so they feel like they are part of a physical community. Online, those who equate straight-edge with political activism often post calls to action or criticisms referring to $\mathrm{SXe}$ as a movement of solidarity. Individuals to whom I spoke who reject the collectivism of straight-edge view it as negative social elitism. Tracy, who has been straight-edge since 1986, distrusts the mob mentality that often arises at shows or on the message boards:

I hate to think of straight-edge as a movement. To me that seems like a cult or religion, where everyone is told exactly what to do and what to think. I'm doing this for me, not for some stranger halfway across the country that thinks straight-edge means beating up everyone who doesn't agree with him. ${ }^{6}$

For many straight-edgers, especially those in smaller cities or remote areas, the online straight-edge community is their only link to other youth that share their value system. Four out of five of my personal contacts told me they knew of no other straight-edgers apart from the Internet friends they have made. Even Tracy, who believes that "most of what is on the Internet regarding straight-edge is bullshit," chooses to seek out http://www.straightedge.com as an occasional source of news and support. Whether or not they would like to admit it, it is clear that by choosing the label of straight-edge, these youth also are participating in the collective ideology that comes with it.

So why are youth drawn to straight-edge? Some common reasons given by people to whom I talked include desiring a structure other than religion in their lives, a way to provide a positive example for other youth, or following in the footsteps of other people they know and respect who are straight-edge. Jessica, age 19, grew up with an alcoholic mother and looks to her online straight-edge friends for support in family matters. Others find support to overcome their own past addictions. Tracy originally got involved with the subculture when she was fourteen: 
I mostly was sXe because it was a reaction against all the "popular," rich kids in my area, all of whom did a lot of drugs and partied a lot. A good way of rebelling. Plus, all my friends were straight-edge. I got irritated with the close-mindedness of many of them and started drinking at age 18. I drank for two years, almost died from overdoses, and stopped again in 1992. This time, straight-edge is more of a way to develop a positive lifestyle. This time, none of my friends are straightedge. $^{7}$

According to some straight-edgers, past addictions immediately disqualify you from the label. IanX believes that "if you slip up you sell out, and if you sell out then you can't call yourself straightedge anymore. That's basically it. There's no turning back" ("straight-edge FAQ," sec. 3-14). But "slipping up" is generally considered by most straight-edgers to be a life experience which adds to one's current straight-edge dedication.

\section{Origins of Straight-edge}

In his essay on subcultural style, John Clarke argues that youth cultures generate particular identities not only through the internal processes within the group itself, but also from interactions with and negative reactions to other groups, events, and ideas (180). The straight-edge subculture developed out of the Washington D.C. punk and hardcore scene of the early 1980s in just such a way. Disgusted by the atmosphere of drugs, alcohol, and nihilistic attitudes prevalent at punk shows, Ian MacKaye and his hardcore band, Minor Threat, began promoting a "stay punk, stay clean" philosophy in their music. In 1981, MacKaye wrote a song titled "Straight Edge," the lyrics of which distinguished him and his band from the larger punk community:

I'm a person just like you

But I've got better things to do

Than sit around and fuck my head

Hang out with the living dead

Snort white shit up my nose

Pass out at the shows

I don't even think about speed

That's something I just don't need

I've got the straight edge.

I'm a person just like you

But I've got better things to do

Than sit around and smoke dope

'Cause I know I can cope

Laugh at the thought of eating ludes

Laugh at the thought of sniffing glue

Always gonna keep in touch

Never want to use a crutch

I've got the straight edge. 
Though Minor Threat disbanded over a decade ago, their music and straight-edge philosophy still influence and support many youth who wish to resist what they consider to be vices of destruction. The band's original rallying chant, "don't drink/don't smoke/don't fuck," has been internalized, debated, reinterpreted, and revered as prophetic by straight-edge youth so intensely-and so literally - that Ian MacKaye has since largely disowned the culture. In an interview with Touch and Go zine, he stated that he never intended for people to take his ideas to such an extreme:

... as far as I'm concerned, all we did was put out an idea. Straight-edge to me is someone who is alert enough to benefit from what he or she is doing... A lot of people think that to be straight-edge you can't drink, smoke, or have sex and that's silly. What the "don't fuck" thing is, is that the whole getting laid and getting head thing - following your penis around - is fucking people up more than anything. (qtd. in "straightedge FAQ," sec. 1)

Regardless of this apparent abandonment by its founder, straight-edge continues to expand and evolve stylistically as a subculture to fit its members' immediate needs.

\section{Staying True to the $\mathrm{X}$}

According to Clarke, youth subcultures rely on elements of style, such as dress, music, demeanor, and rituals, to create a group identity and differentiate themselves from other youth cultures. The most significant and readily-visible style element of the straight-edge subculture is the ritual of putting black magic marker "X"s on the back of one's hands. Originating from the mark given to minors at all-ages punk shows by bar staff to ban them from drinking, voluntary "Xing up" became not only an act of distinction from those who consumed alcohol, but also one of solidarity between fellow straight-edgers. Some individuals wear the symbol of the X or "XXX" on a beaded necklace or a t-shirt, or even tattoo it on their body. Jessica sees her XXX necklace as way to educate others about straight-edge: "People ask me why I have the Xs on there - they think its some kind of pornography thing - and I get to explain to them what it stands for."8

Many straight-edgers refrain from displaying the $\mathrm{X}$ on their person for one reason or another. According to one message-board poster, the importance of the act is relatively arbitrary: "Just X up whenever you feel the urge. There's no standard or anything." "9 Tracy, a 27-year-old sXe, says she never Xs up because she doesn't want to present herself as "better" than anyone else. ${ }^{10}$ Jess, a 20 -year-old from Wisconsin, feels that because he lives in an area virtually oblivious to the subculture, wearing the $\mathrm{X}$ would be a hollow act:

I'm not massively adamant about showing that I'm sXe, if only because

I know that changing people's minds doesn't come through t-shirt

statements or Xs on my hands. It comes through discussion and internal reflection. ${ }^{11}$

Overall, "to X or not to X" seems to be a personal choice of the individual 
depending on how recognizably straight-edge he or she wishes to be perceived both within and outside the community.

Because their clothing is generally similar to the DIY punk style of antifashion, anti-corporate label, X-less straight-edgers often appear indistinguishable within the regular punk/hardcore crowd. Yet while punk fashion usually represents a working-class aesthetic to its participants, many members of the straightedge community choose this type of dress because they are politically opposed to the fashion industry's participation in global capitalism. To the alt.punk.straightedge FAQ, "What do you guys wear?" one respondent commented:

Why all the corporate crap? Yeah, support the corporate sweatshops and union busters! That's really helping the world. I'm not going to mention what I wear, because the only important thing is the Xs on my hands. To any newcomers reading this, please don't take these answers as rules. It doesn't matter what you wear, and there's no reason in the world to go out of your way to find certain corporate shit. (McMann qtd. in "straight-edge FAQ," sec. 1-5)

Straight-edgers, like the larger punk movement, are generally reluctant to rely on material elements of style to signify themselves as a subculture. Many individuals I spoke to expressed awareness of how subcultures that rely heavily on easily-marketable style elements (such as fashion or music) often experience the commodification - and consequent loss of symbolic meaning - of these objects by the mainstream consumer culture. Respondents frequently stressed how straight-edge affected their political and ideological beliefs more than their physical appearance:

Assigning uniforms to the various scenes is relatively easy and many that belong to these scenes are as easily identifiable as the culture they are seeking to subvert. If you see an individual that you think looks sXe, ask them what their beliefs are and why. Challenge them on the real issues that affect society - not fashion sense and personal conduct. (ToddX qtd. in "straight-edge FAQ," sec. 4)

The rejection of surface trivialities and a focus on "the real issues" draws straight-edgers to another element of style: hardcore music. Fast, powerful, and infused with thought-provoking lyrics, hardcore provides youth with "a vital outlet for rage and sadness against abusive and/or dysfunctional political, societal and family structures" ("straight-edge FAQ," sec. 2).

\section{The Hardcore message}

Sitting down on a couch, you watch, a fucking slave to a TV show.

You thought before but you sat and dropped.

What did you learn?

You don't even know, now I kid myself but my eyes are glued on this thing.

It steals my time and wastes what I've learned.

I'm holding out for a better deal, for something real. 
You know I'd like to say that I could spend a day at home with it left off.

How strong's our will?

I can't fit in with the ads I see.

They're better looking than me.

You try to look your best, but you'll never rest. Think; it won't make you happy.

A standard set that I just cannot live up to.

(Gorilla Biscuits, "Stand Still”)

Hardcore music gained prominence in the early 1980s as "second-wave punk," with bands such as Black Flag, Minor Threat, Sick of It All, Bad Brains, the Rollins Band, and Fugazi (Ian MacKaye's band after Minor Threat). Fans describe the subcategory as "sloppier" and "less-arty" than earlier punk bands such as the Sex Pistols, New York Dolls, and The Clash, and as an "uncompromising punk attitude combined with social activism" ("straight-edge FAQ," sec. 1-2). Since its inception, hardcore has been further classified as "old school" and "new school," the latter being more heavy metal-oriented than the former.

Theoretically, hardcore bands raise issues of conflict and hypocrisy witnessed at shows and in the mass media with politically-charged and confrontational lyrics. Musically, however, the genre's oft-repeated description of "substance over style" usually translates into indecipherable shouting blanketed by grinding guitars and furious drums - making it absolutely impossible to grasp the meaning of the lyrics without a written copy of them close at hand. According to Lantrel, who has been going to hardcore shows for five years, this is part of why he likes the music:

Anyone who calls hardcore "noise" doesn't get the point. Everyone at the show probably knows every single lyric by heart, and so everyone in the pit is on the same wavelength as the band. It's so amazingly powerful. If you don't feel the energy of the message, you need to go do your homework. ${ }^{12}$

This "homework" is what Sarah Thornton would call subcultural capital, a term she fashioned after Pierre Bourdieu's theory of cultural capital. Subcultural capital is the level of "hipness" a member of a subculture achieves by being "in the know" about particular elements of his or her scene. ${ }^{13}$

An ongoing debate within the straight-edge community is whether or not someone who considers himself or herself part of the subculture must like hardcore music. While not all hardcore music is technically straight-edge, virtually every self-described straight-edge band categorizes themselves as hardcore. Minor Threat (now defunct), Gorilla Biscuits, Youth of Today, Stretch Armstrong, Snapcase, Earth Crisis, and H20 are some of the more prominent straight-edge hardcore bands in the scene today and many believe them to be required listening to an extent:

If you're sXe and have never listened to the bands that started it, it's kinda like being a communist without ever reading Marx. You gotta 
know your history, even if you aren't into it. ${ }^{14}$

Some individuals I spoke to consider hardcore shows to be a crucial gathering place for their local straight-edge community, while those who see straight-edge as a personal philosophy rather than a social group (and thus are less invested in the process of subcultural capital) are more likely express indifference to hardcore music.

Straight-edge youth who like hardcore music are usually attracted to bands that communicate messages they find provocative or parallel to their own beliefs. When discussing straight-edge issues within the community, it is not uncommon for some individuals to refer to a band's lyrics to highlight their point, as in "as Stretch Armstrong sings...". Straight-edge bands are differentiated by fans through the particular atmosphere they nurture at shows or certain causes they champion in their music. For instance, Earth Crisis is one of the predominant voices in the vegan straight-edge movement, often singing about animal rights and vivisection. In their song, "Degradation," Gorilla Biscuits describes how racism degrades the hardcore scene in New York.

One of the loudest criticisms of straight-edge bands like Youth of Today by hardcore fans is their aggressive intolerance towards those who don't share their views. The band Youth of Today is notorious for picking fights with audience members whom they see drinking or smoking cigarettes, often urging for others to join in. The band Gorilla Biscuits is praised on a fan website as one of the only straight-edge bands that doesn't participate in the usual judgment and superiority over non-straight-edge audience members. Likewise, the band $\mathrm{H} 20$ is well-known for their peaceful, female-friendly pit and relatively laid-back atmosphere.

\section{Hardline Justice and Mass Media Moral Panic}

Though the majority of straight-edge youth I talked to stressed the prevailing non-violence of their subculture, aggressive and violent intolerance is a recurring theme among many of the discussions in the community. A selfproclaimed subdivision of straight-edge, known as hardline, is responsible for much of this criticism. According to the "Hardline Creed" this eco-defense movement, which stresses veganism and pro-life activism is:

a way of life that lives by one ethos - that all innocent life is sacred, and must have the right to live out its natural state of existence in peace, without interference. Any action that does interfere with such rights shall not be considered a "right" in itself, and therefore shall not be tolerated. Those who hurt or destroy life around them, or create a situation in which that life or the quality of it is threatened shall from then on no longer be considered innocent life, and in turn will no longer have rights... Along with this purity of everyday life, the true hardliner must strive to liberate the rest of the world from its chains - saving lives in some cases, and in others, dealing out justice to those guilty of destroying it. ("straight-edge FAQ," sec. 4-6)

"Justice" for hardliners includes releasing captive animals, slashing tires of bar 
patrons (whom they believe will later drive drunk), and physically injuring any other individuals whom they see challenging their "rights" for purity. While this extreme belief system is vehemently despised by the majority of straight-edgers, the "direct actions" of a few hardline youth inexorably stigmatizes the whole straight-edge subculture in the eyes of the parent society.

The Salt Lake City straight-edge scene includes many members who, while they don't technically consider themselves hardline, clearly follow the ideologies of the Hardline Creed. One individual in particular, who calls himself "SLCSE," is a frequent message poster on http://www.straightedge.com.

Following are a sampling of a few of his regular comments:

We use violence as a tool, not as a toy.

(posted March 3, 2000)

Killing one person who is doing wrong in order to save the life of even one or more who is doing right, is just.

(posted March 5, 2000)

[If] you kill a drunk or disable him enough that he cannot walk, let alone drive, then he cannot run over anyone or kill anyone else.

(posted March 6, 2000)

Kids have died at the hands of Salt Lake City Straight-edge.

(posted March 4, 2000)

Given the medium of the Internet message board, inflammatory statements like the ones above should be taken with a proverbial grain of salt. SLCSE refused to talk directly to me about his beliefs, but after reading three month's worth of similar postings, I began to detect an element of exaggerated performance in his arguments. Nevertheless, additional postings by individuals directly familiar with the Salt Lake City straight-edge culture have confirmed that the overriding atmosphere in the scene is one of violent intolerance.

Not surprisingly, the popular media - which remained fundamentally oblivious to straight-edge for the greater part of the subculture's existence - has been quick to detect this faction of troubled youth. In 1999, ABC's news program, 20/20, ran a special segment on Salt Lake City straight-edge. Anchor Hugh Downs introduced the topic with grim seriousness:

What parents wouldn't like their teenager to live a clean, healthy life, swearing off cigarettes and drugs and alcohol? Well, a movement called Straight Edge encourages kids to do just that. Straight Edge sounds like a parent's dream come true. So why are many people and a lot of law enforcement officials afraid of it? John Quinones has a terrifying story of Straight Edge followers going way over the edge in their passion for what they believe in. (20/20 transcript)

Later in the segment, reporter Quinones asks rhetorically, "Who are these Straight Edgers? Well, they don't have gang leaders, and they remain rather elusive." University of Utah Sociology Professor Theresa Martinez, a specialist in street gangs who has been reportedly "tracking the straight-edge movement for five years," provides the expert opinion to the television audience: "If you strip away the message, in many ways, this is just another gang. Straight Edge is just 
another gang."

Admittedly, 20/20 should be allowed a certain amount of credit for their presentation of this segment. The content of the story centered on a particularly violent scuffle instigated by Salt Lake City straight-edgers towards some fraternity brothers who asked them for a cigarette lighter. As illustrated earlier by SLCSE's message board posts, perhaps the violent members of the Salt Lake City straight-edge subculture should be considered a menacing "gang" by society. To retain some level of fairness, frequent mention was made during the broadcast that straight-edge in other parts of America are generally positive, non-violent youth organizations. Yet in light of the predominant negativity of the segment, how many television viewers previously unfamiliar with straight-edge walked away with a fair and balanced conception of the subculture?

Unfortunately, perhaps the most resonant summation of the mass media's relationship to straight-edge is this: a content search for straight-edge on the ABC News website returns one solitary document with the title "Hate Symbols." On the page appears the symbol "XXX" with a subtitle that reads, "A tattoo worn to show affiliation with the Straight Edge movement, some followers of which promote racism and intolerance" (ABC.com). As the 20/20 credits roll and American popular culture files straight-edge into some vague and overflowing "menace to society" receptacle in its collective brain, thousands of clean and sober sXe kids shrug and laugh bitterly; they never wanted to be popular anyway.

\section{Concluding Thoughts and Parting Questions}

This paper is my valiant attempt to outline and initiate a discourse on a subculture I personally believe to be both wondrously complex and maddeningly problematic. I wish to thank my contacts: Joe, Jess, Lantrel, Jessica, Tracy, and Kaitlin for answering endless questions and challenging me to answer some of theirs. Numerous questions remain in relation to the straight-edge subculture, some of which include: What changes take place for sXe youth as they get older? How do components of one's race, gender, class, and sexuality converge with straight-edge ideologies? How does geographical region affect straight-edge community building? How do the experiences and concerns of online straightedge culture compare to those on the other side of the digital divide?

\section{Works Cited}

alt.punk.straight-edge FAQ < http://www.faqs.org/faqs/cultures/straight-edgefaq $>$

ABC News.com <http://more.abcnews.go.com/sections/us/hate_group/ hate_symbols29.html>

Bourdieu, Pierre. In Other Words: Essays Towards a Reflexive Sociology. London: Polity, 1990.

Clarke, John. "Style." Resistance through Rituals: Youth subcultures in postwar Britain. Eds. Stuart Hall and Tony Jefferson. London: Routledge, 1991. 175-191. 
Griffin, Christine. Representations of Youth: The Study of Youth and Adolescence in Britain and America. Cambridge: Polity Press, 1993.

McRobbie, Angela. "Settling Accounts with Subcultures: A Feminist Critique."

On Record: Rock, Pop, and the Written Word. Ed. Simon Frith and Andrew Goodwin. New York: Routledge, 1990. 66-80.

Straightedge.com $<$ http://www.straightedge.com>

Thornton, Sarah. club cultures: Music, Media and Subcultural Capital. Hanover: Wesleyan University, 1996.

20/20 Transcript $<$ http://xsxex.net/article/abcsxe.txt $>$

\section{Notes}

${ }^{1}$ See Angela McRobbie's "Settling Accounts with Subcultures: A Feminist Critique" and Sarah Thornton's Club Cultures: Music, Media and Subcultural Capital.

${ }^{2}$ Straight-edge may also be referred to as straightedge, straight edge; or abbreviated as sXe.

${ }^{3}$ Joe, email correspondence, March 30, 2000.

${ }^{4}$ Email correspondence, March 24, 2000.

${ }^{5}$ Email correspondence, April 4, 2000.

${ }^{6}$ Email correspondence, March 24, 2000.

7 ibid.

${ }^{8}$ Email correspondence, March 29, 2000.

${ }^{9}$ Posted by xativeganx on http://www.straightedge.com, March 22, 2000.

${ }^{10}$ Email correspondence, March 24, 2000.

${ }^{11}$ Email correspondence, March 31, 2000.

${ }^{12}$ Email correspondence, March 24, 2000.

${ }^{13}$ For a more detailed discussion of this term, see Sarah Thornton's Club Cultures, 11-14.

${ }^{14}$ Posted by TDS on http://www.straightedge.com, March 3, 2000.

\section{Personal Contacts}

Jessica, female, 19, Alabama.

Jess, male, 20, Wisconsin.

Joe, male, 18, Ohio.

Kaitlin, female, 17, Pennsylvania.

Lantrel, male, 24, California.

Tracy, female, 27, New York. 